\title{
Chemokine receptor 7 via proline-rich tyrosine kinase-2 upregulates the chemotaxis and migration ability of squamous cell carcinoma of the head and neck
}

\author{
LIANGLIANG YANG, FAYU LIU, ZHONGFEI XU, NAN GUO, XIAOJIAO ZHENG and CHANGFU SUN \\ Department of Oromaxillofacial-Head and Neck Surgery, Department of Oral and Maxillofacial Surgery, \\ School of Stomatology, China Medical University, Shenyang, Liaoning 110002, P.R. China
}

Received May 23, 2012; Accepted July 10, 2012

DOI: $10.3892 /$ or.2012.1989

\begin{abstract}
Aberrant regulation in the chemotaxis and migration ability of cancer cells is closely associated with their metastatic activity. The chemokine receptor 7 (CCR7) has recently been shown to play an important role in regional lymph node metastasis of squamous cell carcinoma of the head and neck (SCCHN). In this study, we examined the role of proline-rich tyrosine kinase-2 (Pyk2) in CCR7-induced chemotaxis and migration ability of metastatic SCCHN cells. We showed that Pyk2 is overexpressed in squamous cell carcinoma of the head and neck. We also found that CCR7 induced Pyk2 and cofilin activation. Inhibition of Pyk 2 activity using a pharmacological inhibitor, Tyrphostin A9, significantly attenuated CCR7-induced Pyk2 tyrosine phosphorylation, activation of cofilin and sequentially abolished F-actin rearrangment, diminished the chemotaxis and migration ability of SCCHN cells. In summary, our data suggest that CCR7 via Pyk2 and cofilin regulates the chemotaxis and migration ability of metastatic SCCHN cells.
\end{abstract}

\section{Introduction}

The 5-year survival for patients with squamous cell carcinoma of the head and neck is only $30 \%$, mainly due to the frequent presence of metastasis at diagnosis (1). The pattern of regional cervical metastasis in this disease is remarkably consistent. A better understanding of this unique metastatic process is necessary to enable the development of therapies designed to prevent tumor dissemination.

Chemokines and their respective receptor that regulate chemotaxis and the transendothelial migration of leukocytes during immune and inflammatory reactions were recently

Correspondence to: Dr Changfu Sun or Dr Fayu Liu, Department of Oromaxillofacial-Head and Neck Surgery, Department of Oral and Maxillofacial Surgery, School of Stomatology, China Medical University, No. 117, Nanjing Bei Jie, Heping District, Shenyang, Liaoning 110002, P.R. China

E-mail: changfusun@hotmail.com

E-mail:1fyhjk@126.com

Key words: chemokine receptor 7, squamous cell carcinoma of the head and neck, migration, proline-rich kinase-2, actin cytoskeleton observed to play an important role in the metastasis of various types of cancer $(2,3)$. Chemokine receptors have been found to be expressed in these invasive cells in a distinct and nonrandom pattern. In particular, metastatic SCCHN cells have been shown to express chemokine receptor 7 (CCR7), which may enable their access to the lymphatic system and facilitate spread to regional lymph nodes (4-7). However, the signaling mechanisms mediated by CCR7 and induced by CCL19 have yet to be elucidated in SCCHN cells.

Proline-rich kinase-2 (Pyk2) is a non-receptor protein tyrosine kinase structurally related to focal adhesion kinase. Pyk2 has a restricted tissue expression primarily in neuronal and hematopoietic tissues. The tyrosine 402 (Y402) at Pyk2 serves as the primary autophosphorylation site that is essential for Pyk 2 activity and function (8). Pyk 2 is rapidly activated by G-protein coupled receptor agonists, growth factors, cytokines and stress signals, thus regulating various functions such as cell adhesion, migration, proliferation and survival $(9,10)$. Pyk2 is also involved in regulating the migration and invasion of human glioma, prostate and breast cancer cells (11-13). It has previously been demonstrated that the activaton of Pyk 2 by CCR7 was involved in dendritic cells (DC) (14). Therefore, we hypothesized that Pyk2 might be involved in CCR7 mediated signals in SCCHN cells. Our results showed that CCL19 induced the activation of Pyk2 and the activation of cofilin which altered actin cytoskeletal rearrangement, and this signal pathway was crucial for the chemotaxis and migration of SCCHN cells.

\section{Materials and methods}

Cell line and human tumor samples. The metastatic SCCHN cell line PCI-37B, which strongly expresses CCR7, was a kind gift from the University of Pittsburgh. Cells were cultured in DMEM medium (Invitrogen, Carlsbad, CA, USA), which contained $10 \%(\mathrm{v} / \mathrm{v})$ heat-inactivated fetal bovine serum (Gibco-BRL Corp., Grand Island, NY, USA), 100 U/ml penicillin and $100 \mathrm{U} / \mathrm{ml}$ streptomycin.

Sixty specimens of SCCHN tumors with the adjacent metastatic (or normal) lymph nodes and 10 specimens of normal human oral mucosal tissue were obtained from the Head and Neck Tumor Center, School of Stomatology, China Medical University. All the specimens were obtained with the 
Table I. Correlation between Pyk2 expression and clinicopathological factors of SCCHN.

\begin{tabular}{|c|c|c|c|c|}
\hline $\begin{array}{l}\text { Clinicopathological } \\
\text { characteristics }\end{array}$ & No. of cases & + to +++ & - & $\begin{array}{l}\text { Statistical analysis } \\
\left.\text { ( } \chi^{2} \text { test }\right)\end{array}$ \\
\hline \multicolumn{5}{|l|}{ Age (years) } \\
\hline$\geq 60$ & 36 & 20 & 16 & \multirow[t]{2}{*}{0.049} \\
\hline$<60$ & 24 & 15 & 9 & \\
\hline \multicolumn{5}{|l|}{ Tumor size } \\
\hline $\mathrm{T} 1, \mathrm{~T} 2$ & 49 & 28 & 21 & \multirow[t]{2}{*}{0.156} \\
\hline $\mathrm{T} 3, \mathrm{~T} 4$ & 11 & 7 & 4 & \\
\hline \multicolumn{5}{|l|}{ Clinical stage } \\
\hline I, II & 28 & 11 & 17 & \multirow[t]{2}{*}{$7.837^{\mathrm{a}}$} \\
\hline III, IV & 32 & 24 & 8 & \\
\hline \multicolumn{5}{|l|}{ Nodal metastasis } \\
\hline No & 30 & 11 & 19 & \multirow[t]{2}{*}{$11.589^{\mathrm{a}}$} \\
\hline Yes & 30 & 24 & 6 & \\
\hline
\end{tabular}

${ }^{\mathrm{a}} \mathrm{P}<0.05$ (the internal difference of Pyk2 expression within clinicopathological characteristics).

consent of the patients before surgery and in accordance with Health Insurance Portability. The classification of SCCHN, including primary tumors $(\mathrm{T})$, regional lymph nodes $(\mathrm{N})$, distant metastasis (M) and stage grouping, was determined according to the rules of the International Union Against Cancer (UICC) for Head and Neck Cancer (tumor node metastasis, TNM classification, 1997).

Reagents and antibodies. The CCR7 chemokine ligand (CCL19, MIP-3 $\beta$ ) and the anti-hCCR7 mAb were purchased from R\&D Systems (Minneapolis, MN, USA). The Pyk2 inhibitor (Tyrphostin A9) was purchased from Calbiochem (San Diego, CA, USA). Anti-Pyk2, anti-phospho-Pyk2(402) and anti-p-cofflin were bought from Santa Cruz Biotechnology (Santa Cruz, CA, USA). TRITC-labelled phalloidin was from Sigma (St. Louis, MO, USA).

Chemotaxis assay. Chemotaxis in response to chemokine was determined by measuring the number of cells migrating through a polycarbonate filter $(8-\mu \mathrm{m}$ pore size $)$ in 24 -well transwell chambers in triplicate in DMEM with $0.5 \%(\mathrm{w} / \mathrm{v})$ BSA (Invitrogen). The cell suspensions $\left(2 \times 10^{5}\right.$ cell/200 $\left.\mu \mathrm{l}\right)$, were placed in the top chamber of the filter. Aliquots of the chemokine were added to the wells. After $24 \mathrm{~h}$, cells in each lower well were counted under a light microscope in at least five different fields (original magnification, $x 200$ ). The mean \pm SD was recorded for each condition, and index calculated based on the control, random migration.

Matrigel invasion assay. Cell invasion was quantified in vitro using Matrigel-coated semipermeable, modified inserts with a pore size of $8 \mu \mathrm{m}$. The analysis of invasion assay was performed as described in the chemotaxis assay incubated with CCL19 for $36 \mathrm{~h}$.

Western blotting. Briefly, 70-80\% confluent cells were serumstarved for 24 h. Following treatment, cells were lysed in M-PER reagent (Pierce) containing $1 \mathrm{mM}$ PMSF and phosphatase inhibitors and centrifuged at $4^{\circ} \mathrm{C}, 12,000 \mathrm{rpm}$ for $30 \mathrm{~min}$. The supernatant protein was normalized and $80 \mu \mathrm{g}$ of protein was size-fractionated and immunoblotted with the indicated mAbs, we determined Pyk2, p-Pyk2(402) and p-cofilin protein expression.

Actin polymerization assay. PCI-37B cells pretreated with/ without CCR7 mAb and Pyk2 inhibitor Tyrphostin A9 were fixed, permeabilized and stained with TRITC-labeled phalloidin. Following labeling, the samples were washed three times for $10 \mathrm{~min}$ each in PBS to remove the unincorporated label. F-actin distribution following CCL19 stimulation was evaluated by confocal laser scanning microscope (CLSM, Leica SP2, Germany).

Immunohistochemical analysis. Immunohistochemical staining used conventional horseradish peroxidase immunohistochemical staining methods. In brief, 5- $\mu \mathrm{m}$ sections of the specimens were deparaffinized and hydrated with $0.6 \% \mathrm{H}_{2} \mathrm{O}_{2}$ in methanol to inhibit endogenous peroxidase, performed antigen retrieval and incubated with normal blocking serum for $10 \mathrm{~min}$. The sections were then incubated with primary antibodies (1:100): rabbit anti-Pyk2 polyclonal antibody overnight at $4^{\circ} \mathrm{C}$. Immunodetection was performed using peroxidase labeled secondary antibody (R\&D Systems) and diaminobenzidine for visualization. All the sections were counterstained with hematoxylin (Sigma). Negative controls included omission of the primary antibody. The cell morphology was analyzed by microscopy (Nikon Eclipse 80i, Tokyo, Japan) at x100-400 magnification. According to the percentage of positive tumor cells, all these cells were scored as negative $(-),<10 \%$ or no staining; weak positive $(+), 11-50 \%$; positive $(++), 51-75 \%$; or strongly positive $(+++),>75 \%$.

Statistical analysis. Numerical data were expressed as the mean \pm standard deviation (SD). Statistical differences between two groups were evaluated using Student's t-test. Correlation 


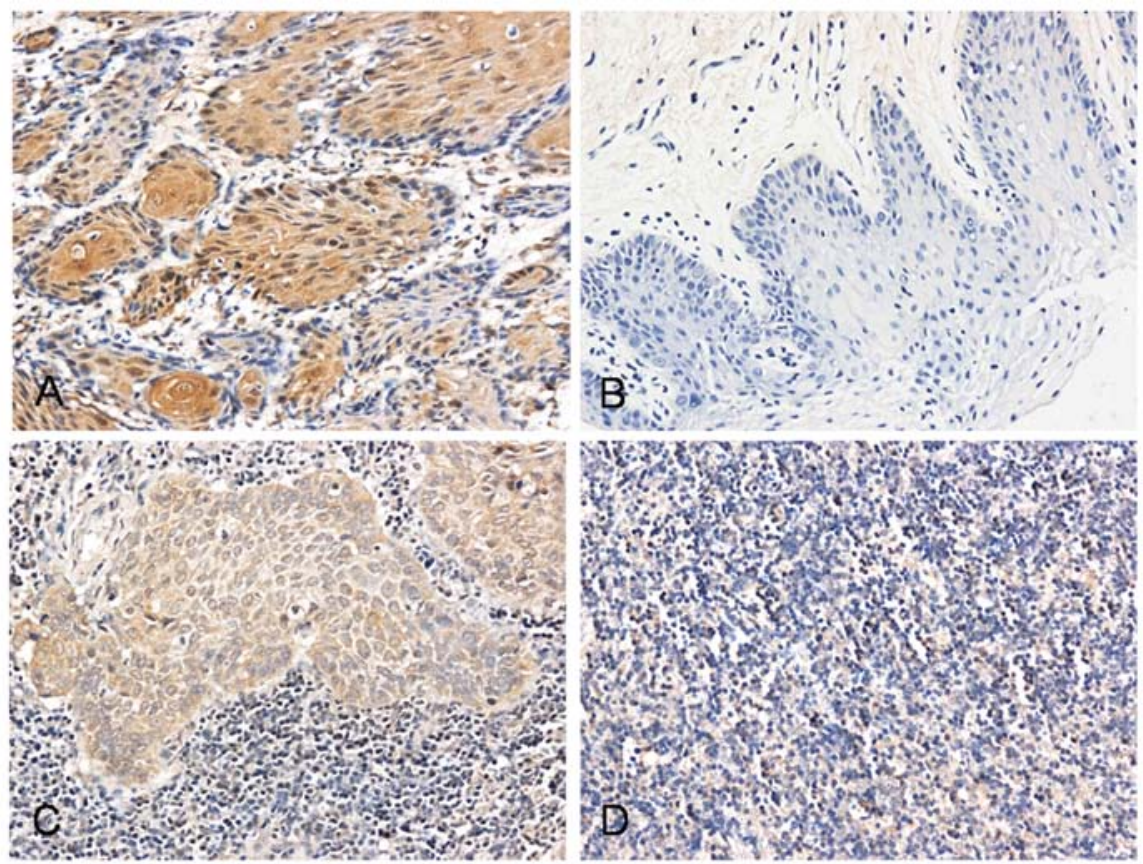

Figure 1. Immunohistochemical staining of Pyk2 in (A) primary SCCHN, (B) normal tissues, (C) metastatic lymph nodes and (D) normal lymph nodes (original magnification, $\mathrm{x} 200$ ).

A

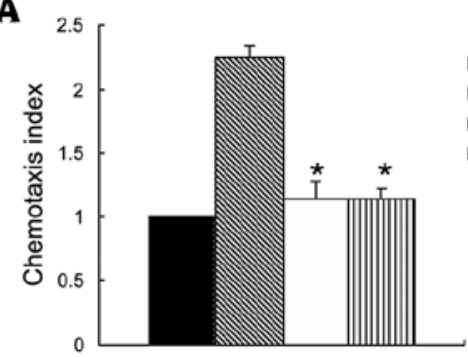

B

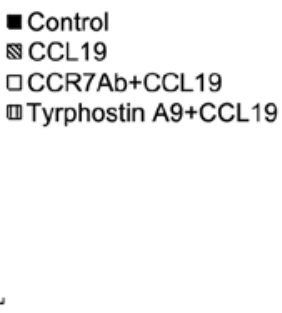

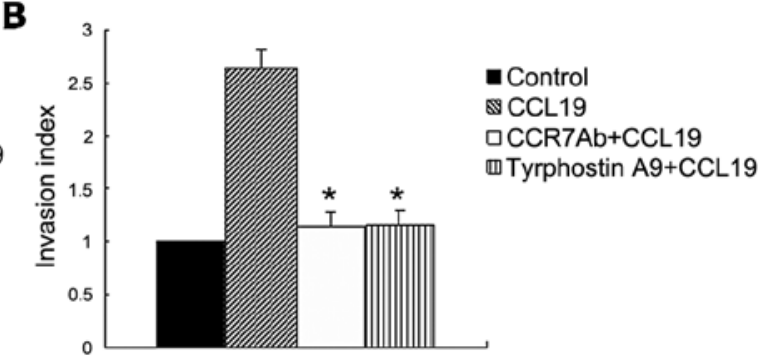

Figure 2. Tyrphostin A9 diminished the CCR7-induced chemotaxis and invasion ability of PCI-37B cells. PCI-37B cells were pretreated with CCR7 Ab $\left(10 \mu \mathrm{g} / \mathrm{ml}\right.$, at $37^{\circ} \mathrm{C}$ for $\left.4 \mathrm{~h}\right)$ or Pyk2 inhibitor Tyrphostin A9 $\left(10 \mu \mathrm{M}\right.$, at $37^{\circ} \mathrm{C}$ for $\left.1 \mathrm{~h}\right)$, then followed by CCR7 ligand, CCL19 (500 ng/ml), as a chemoattractant and DMEM media alone as the blank control. (A) Chemotaxis assay chambers were incubated at $37^{\circ} \mathrm{C}$ for $24 \mathrm{~h}$. (B) In vitro invasion assay chambers were incubated at $37^{\circ} \mathrm{C}$ for $36 \mathrm{~h}$. Results are shown as the mean $\pm \mathrm{SD} n=3,{ }^{*} \mathrm{P}<0.01$. Comparison of treatment of cells with CCR7 Ab or Tyrphostin A9 to treatment of cells with CCL19 alone.

between Pyk2 expression and SCCHN clinical stage was analyzed by $\chi^{2}$ test. Values of $\mathrm{P}<0.05$ were considered to indicate statistically significant differences. All statistical analyses were performed with the software SPSS 13.0.

\section{Results}

Pyk2 is overexpressed in squamous cell carcinoma of the head and neck. Using immunohistochemistry, we investigated the expression of Pyk 2 in SCCHN tumor tissues, metastatic lymph nodes, normal lymph nodes and oral mucosal tissues. Pyk2 was found in the cell membrane and cytoplasm in tumor cells and lymph node metastatic cells. The number of stained cells was low or absent in normal lymph nodes and oral mucosal tissues (Fig. 1 and Table I). The expression of Pyk 2 was significantly correlated with cervical lymph node metastasis and SCCHN clinical stage $(\mathrm{P}<0.05)$
Correlation of the migration ability and the activities of CCR7 and Pyk2 in the metastatic SCCHN cell line. To investigate the molecular mechanism that regulates the chemotaxis and migration ability of SCCHN, we utilized the metastatic tumor cell line (PCI-37B) which expresses CCR7, then analysed their capability to migrate in vitro in response to the respective chemokine ligand CCL19. This experiment showed that CCL19 enhanced chemotaxis of SCCHN significantly as compared with background control levels established with media alone. The Pyk2 inhibitior and anti-CCR7 mAb significantly blocked CCL19-induced cell chemotaxis, as shown in Fig. 2A.

In addition to chemotactic ability, we evaluated the invasive capacity mediated by CCR7 in the metastatic SCCHN cell line. In vitro invasion through Matrigel was assessed after exposure of these cells to the CCR7 ligand, CCL19, in the presence or absence of Tyrphostin A9 or pretreatment with a CCR7-specific blocking mAb. Fig. 2B shows that treatment of 
A

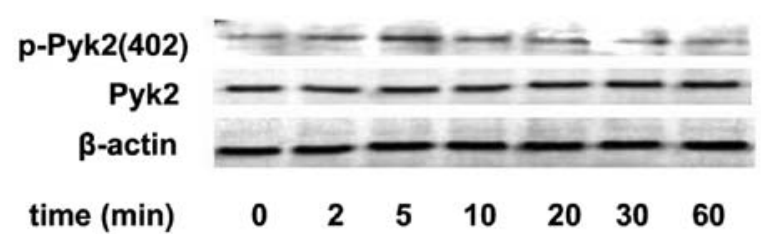

B

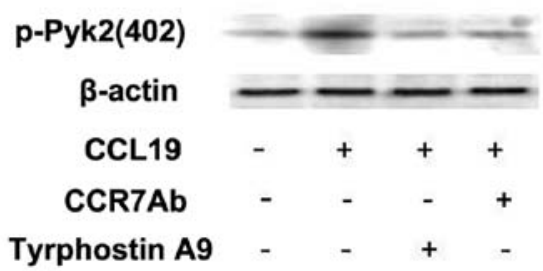

Figure 3. CCR7 stimulated activation of the tyrosine kinase Pyk2. (A) Time course of CCL19-stimulated Pyk2 activity in PCI-37B cells. PCI-37B cells were stimulated for the indicated times with $200 \mathrm{ng} / \mathrm{ml}$ CCL19. (B) Effect of CCR7 Ab on CCL19-induced Pyk2 activations in PCI-37B cells. PCI-37B cells pretreated with/without Tyrphostin $\mathrm{A} 9\left(10 \mu \mathrm{M}\right.$, at $37^{\circ} \mathrm{C}$ for $\left.1 \mathrm{~h}\right)$ or CCR7 $\mathrm{Ab}$ $\left(10 \mu \mathrm{g} / \mathrm{ml}\right.$, at $37^{\circ} \mathrm{C}$ for $\left.4 \mathrm{~h}\right)$ were stimulated with $200 \mathrm{ng} / \mathrm{ml} \mathrm{CCL} 19$ for $5 \mathrm{~min}$.

cells with tyrphostin A9 significantly abolished the CCL19induced invasive capacity $(\mathrm{P}<0.01)$, indicating the invasive capacity mediated by CCR7 required Pyk2 activity.

Role of CCR7 in regulating the Pyk2 activity in metastatic SCCHN. Since tyrosine kinase Pyk2 has been shown to be involved in the signaling from chemokine receptors (11), we examined whether stimulation of metastatic SCCHN cells with CCL19 modulates the activity of this kinase. The metastatic SCCHN cell line (PCI-37B) was stimulated with chemokines for different time periods. We found that CCL19 induced a transient increase in the activity of Pyk2 (Fig. 3A). Autophosphorylation of Pyk 2 increased as early as 2 min after the addition of chemokine to the cells, reached a maximum after 5-10 min and returned to basal levels after $60 \mathrm{~min}$ (Fig. 3A). To define the role of CCR7 $\mathrm{mAb}$ in regulating Pyk2 activity we examined the activity of this kinase in the cells pretreated with/without CCR7 mAb and Pyk2 inhibitor Tyrphostin A9. As shown in Fig. 3B, CCL19 induced Pyk2 activation to a level 2- to 3-fold above the baseline, which was determined by incubation with media alone. Phosphorylation of this molecule was blocked selectively by the Pyk2 inhibitor

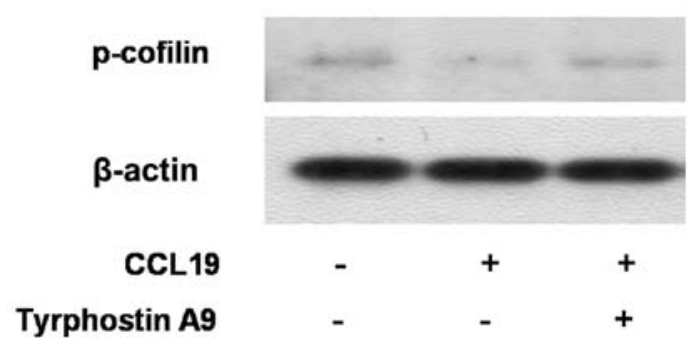

Figure 4. CCL19-induced cofilin activations were blocked by Pyk2 inhibitor in PCI-37B cells. PCI-37B cells pretreated with/without Tyrphostin A9 (10 $\mu \mathrm{M}$, at $37^{\circ} \mathrm{C}$ for $\left.1 \mathrm{~h}\right)$ were stimulated with $\mathrm{CCL} 19\left(200 \mathrm{ng} / \mathrm{ml}\right.$, at $37^{\circ} \mathrm{C}$ for $\left.5 \mathrm{~min}\right)$.

(Tyrphostin A9) and CCR7 mAb. These experiments were repeated at least three times with similar results.

CCR7 inhibits phosphorylation/inactivation of cofilin that is mediated by Pyk2. Cofilin mediates lamellipodium extension and polarized cell migration by stimulating actin filament dynamics at the leading edge of migrating cells. Cofilin is inactivated by phosphorylation at Ser-3. We analyzed whether cofilin is downstream of Pyk2. The western blot experiment showed that CCL19 inhibited phosphorylation/inactivation of cofilin in SCCHN cells. Markedly, Tyrphostin A9 blunted the decrease in phosphorylation of cofilin (Fig. 4), indicating that cofilin is downstream of Pyk2. In summary, the result indicates that CCR7 inhibits phosphorylation/inactivation of cofilin that is mediated by Pyk2.

CCR7 induces F-acin rearrangement. Cell motility involves regulation of the actin cytoskeleton and the actin-severing protein cofilin regulates actin organization. We found that CCR7 activation lead F-actin polymerization and pseudopodia formation. In untreated cells we observed a scattered distribution of F-actin (Fig. 5). In the cells treated with CCL19 F-actin arrays and pseudopodia were formatted, while these effects were blocked by Tyrphostin A9. We therefore consider that the actin cytoskeletal rearrangement induced by CCL19 requires Pyk2.

\section{Discussion}

The chemotaxis and migration ability of tumor cells plays a critical role for successful metastasis (14). CCR7 has been shown to be involved in the metastasis of SCCHN (4), and
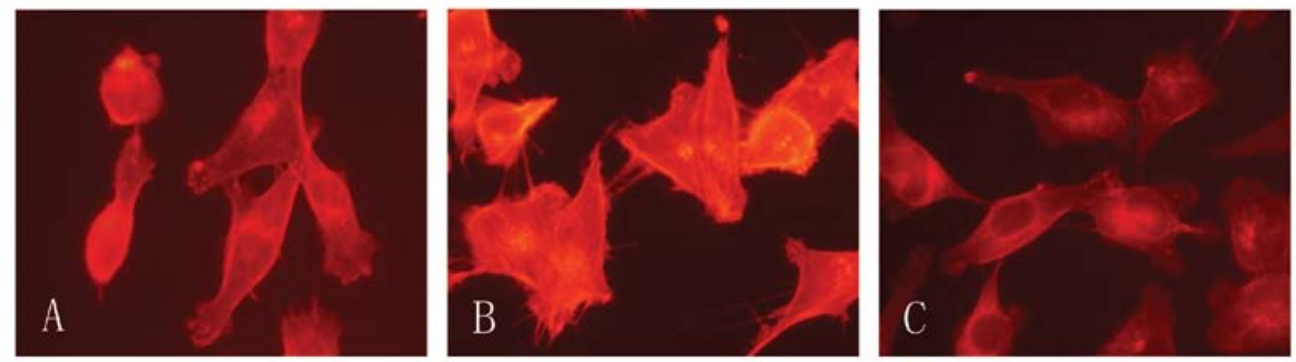

Figure 5. CCL19-induced and Tyrphostin A9 blocked reorganization of the actin cytoskeleton of PCI-37B cells. PCI-37B cells were (A) untreated, (B) treated with CCL19 (500 ng/ml, for $0.5 \mathrm{~h})$, or (C) treated with Tyrphostin A9 (10 $\mu \mathrm{M}$, for $1 \mathrm{~h})$ followed by CCL19 (500 ng/ml for $0.5 \mathrm{~h})$. The cells were stained by Rhodamine-labeled phalloidin. 
previous studies have presented a picture of the function of this gene (15-18). However, the exact role of CCR7 in tumor progression and its underlying mechanism remain unclear. Pyk2 is also involved in regulating the migration and invasion of a variety of different tumor types. ErbB-2 via Pyk2 upregulates the adhesive ability of androgen receptor-positive human prostate cancer cells (19). Pyk2 has been found to be crucial to cell motility and SOCS3 can regulate Pyk 2 pro-migratory function in lung cancer (20). In breast cancer cells, Pyk2 participates in CXCR4-induced chemotactic and chemoinvasive signaling pathways (21). However, there is no report on the role of Pyk2 in SCCHN. Our experiments showed that Pyk2 is highly expressed in SCCHN and metastatic lymph node cells. The expression of Pyk2 was significantly correlated with cervical lymph node metastasis and SCCHN clinical stage. Hence, we considered that Pyk2 is probably crucial for the development and progress of SCCHN.

Tyrosine kinase Pyk2 has been involved in the signaling from chemokine receptors in different cells. In breast cancer cells, CXCL12 induces the phosphorylation at residues 402 and 579/580 of Pyk2, Pyk2 inhibitors significantly blocks CXCL12-induced chemotaxis and chemoinvasion and so the role of Pyk2 is indicated in CXCL12-induced breast cancer cell migration and invasion (22). In T cells, Pyk2 becomes activated in response to chemokine receptors and is important for cell spreading and migration (23). Some results indicate that Pyk 2 acts as a receptor-proximal link between integrin and chemokine receptor signaling, and the Pyk2/Rac pathway plays a pivotal role in the control of NK cell transendothelial migration (24). We examined the role of Pyk2 in CCR7induced metastasis of SCCHN cells. We found that CCL19 (CCR7 ligand) induced the activation of Pyk2 in metastasic SCCHN cells and the actvation was blocked by CCR7 mAb. Then, we used the Pyk2 inhibitor, Tyrphostin A9, to analyze the role of Pyk2 in the chemotaxis and migration of SCCHN cells. The results revealed the predominant role of CCR7 in upregulating the Pyk2 activity which was important for the chemotaxis and migration ability of SCCHN cells. Further experiments are required to clarify if other molecules are involved in the CCR7/Pyk2 pathway.

The actin severing protein cofilin is essential for directing cell migration and chemotaxis in many cell types and is also important for tumor cell invasion during metastasis $(25,26)$. Through its severing activity, cofilin increases the number of free barbed ends to initiate actin polymerization for actin-based protrusion. In this regard, we notably observed that stimulation of CCR7 induced dephosphorylation/activation of cofilin. The Tyrphostin A9 abolished the activation of cofilin, suggesting that Pyk2 is upstream of this molecule. Our results indicate that cofilin may mediate the effects of Pyk2 on cell motility.

A high level of actin polymerization is required for the formation of pseudopodia, which is needed for chemokinemediated cell migration and invasion into surrounding tissues and efficient metastasis formation (27). In our study, we examined rhodamine-labeled phalloidin staining by inverted microscopy, and observed reorganization of the actin cytoskeleton of PCI-37B was enhanced in response to CCL19, and this function was inhibited by Tyrphostin A9. This result, consistent with previous studies in hepatocellular carcinoma, demonstrates that Pyk2 upregulates the formation of pseudo- podia and actin stress fiber polymerization of HCC cells and promotes cell motility (28).

In conclusion, we found that CCR7 promoted tumor metastasis by sequential activation of Pyk2 and cofilin followed by rearrangement of F-actin in SCCHN cells. Our results thus reveal a novel signal pathway that regulates the chemotaxis and migration ability of SCCHN cells and provide potential targets for advanced therapy of squamous cell carcinoma of the head and neck.

\section{Acknowledgements}

This study was supported by grants from the National Natural Science Foundation of China (no. 30672331), the National Science Foundation for Young Scholars of China (no. 81102058) and the Foundation of Education Bureau of Liaoning Province, China (no. 2009A755).

\section{References}

1. Greenlee RT, Hill-Harmon MB, Murray T and Thun M: Cancer Statistics, 2001. CA Cancer J Clin 51: 15-36, 2001.

2. Müller A, Homey B, Soto H, Ge N, Catron D, Buchanan ME, McClanahan T, Murphy E, Yuan W, Wagner SN, et al: Involvement of chemokine receptors in breast cancer metastasis. Nature 410: 50-56, 2001.

3. Ben-Baruch A: Site-specific metastasis formation: chemokines as regulators of tumor cell adhesion, motility and invasion. Cell Adh Migr 3: 328-333, 2009.

4. Wang J, Xi L, Hunt JL, Gooding W, Whiteside TL, Chen Z, Godfrey TE and Ferris RL: Expression pattern of chemokine receptor 6 (CCR6) and CCR7 in squamous cell carcinoma of the head and neck identifies a novel metastatic phenotype. Cancer Res 64: 1861-1866, 2004.

5. Zhao ZJ, Liu FY, Li P, Ding X, Zong ZH and Sun CF: CCL19induced chemokine receptor 7 activates the phosphoinositide-3 kinase-mediated invasive pathway through Cdc42 in metastatic squamous cell carcinoma of the head and neck. Oncol Rep 25: 729-737, 2011.

6. Liu FY, Zhao ZJ, Li P, Ding X, Zong ZH and Sun CF: Mammalian target of rapamycin (mTOR) is involved in the survival of cells mediated by chemokine receptor 7 through PI3K/Akt in metastatic squamous cell carcinoma of the head and neck. Br J Oral Maxillofac Surg 48: 291-296, 2010.

7. Zhen-Jin Z, Peng L, Fa-Yu L, Liyan S and Chang-Fu S: PKCa take part in CCR7/NF- $\kappa \mathrm{B}$ autocrine signaling loop in CCR7positive squamous cell carcinoma of head and neck. Mol Cell Biochem 357: 181-187, 2011.

8. Park SY, Li H and Avraham S: RAFTK/Pyk2 regulates EGF-induced PC12 cell spreading and movement. Cell Signal 19: 289-300, 2007

9. Picascia A, Stanzione R, Chieffi P, Kisslinger A, Dikic I and Tramontano D: Proline-rich tyrosine kinase 2 regulates proliferation and differentiation of prostate cells. Mol Cell Endocrinol 186: 81-87, 2002.

10. Kuwabara K, Nakaoka T, Sato K, Nishishita T, Sasaki T and Yamashita N: Differential regulation of cell migration and proliferation through proline-rich tyrosine kinase 2 in endothelial cells. Endocrinology 145: 3324-3330, 2004.

11. Roelle S, Grosse R, Buech T, Chubanov V and Gudermann T: Essential role of Pyk2 and Src kinase activation in neuropeptideinduced proliferation of small cell lung cancer cells. Oncogene 27: 1737-1748, 2008.

12. de Amicis F, Lanzino M, Kisslinger A, Calì G, Chieffi P, Andò S Mancini FP and Tramontano D: Loss of proline-rich tyrosine kinase 2 function induces spreading and motility of epithelial prostate cells. Cell Physiol 209: 74-80, 2006.

13. Behmoaram E, Bijian K, Jie S, Xu Y, Darnel A, Bismar TA and Alaoui-Jamali MA: Focal adhesion kinase-related proline-rich tyrosine kinase 2 and focal adhesion kinase are co-overexpressed in early-stage and invasive ErbB-2-positive breast cancer and cooperate for breast cancer cell tumorigenesis and invasiveness. Am J Pathol 173: 1540-1550, 2008. 
14. Riol-Blanco L, Sánchez-Sánchez N, Torres A, Tejedor A, Narumiya S, Corbí AL, Sánchez-Mateos $\mathrm{P}$ and RodríguezFernández JL: The chemokine receptor CCR7 activates in dendritic cells two signaling modules that independently regulate chemotaxis and migratory speed. J Immunol 174: 4070-4080, 2005.

15. Wang J, Zhang X, Thomas SM, Grandis JR, Wells A, Chen ZG and Ferris RL: Chemokine receptor 7 activates phosphoinositide- 3 kinase-mediated invasive and prosurvival pathways in head and neck cancer cells independent of EGFR. Oncogene 24 5897-5904, 2005.

16. Liu FY, Zhao ZJ, Li P, Ding X, Guo N, Yang LL, Zong ZH and Sun CF: NF- $\kappa B$ participates in chemokine receptor 7-mediated cell survival in metastatic squamous cell carcinoma of the head and neck. Oncol Rep 25: 383-391, 2011.

17. Li P, Zhao ZJ, Liu FY, Sun LY, Ding X, Zhang WZ, Shang DH and Sun CF: The chemokine receptor 7 regulates cell adhesion and migration via $\beta 1$ integrin in metastatic squamous cell carcinoma of the head and neck. Oncol Rep 24: 989-995, 2010.

18. Li P, Liu F, Sun L, Zhao Z, Ding X, Shang D, Xu Z and Sun C: Chemokine receptor 7 promotes cell migration and adhesion in metastatic squamous cell carcinoma of the head and neck by activating integrin $\alpha v \beta 3$. Int J Mol Med 27: 679-687, 2011.

19. Yuan TC, Lin FF and Veeramani S: ErbB-2 via PYK2 upregulates the adhesive ability of androgen receptor-positive human prostate cancer cells. Oncogene 26: 7552-7559, 2007.

20. Zhang S, Guo D, Jiang L, Zhang Q, Qiu X and Wang E: SOCS3 inhibiting migration of A549 cells correlates with PYK2 signaling in vitro. BMC Cancer 28: 150, 2008.
21. Prasad A, Fernandis AZ, Rao Y and Ganju RK: Slit proteinmediated inhibition of CXCR4-induced chemotactic and chemoinvasive signaling pathways in breast cancer cells. J Biol Chem 279: 9115-924, 2004

22. Fernandis AZ, Prasad A, Band H, Klösel R and Ganju RK: Regulation of CXCR4-mediated chemotaxis and chemoinvasion of breast cancer cells. Oncogene 23: 157-167, 2004.

23. Ostergaard HL and Lysechko TL: Focal adhesion kinase-related protein tyrosine kinase Pyk2 in T-cell activation and function. Immunol Res 31: 267-282, 2005.

24. Gismondi A, Jacobelli J, Strippoli R, Mainiero F, Soriani A, Cifaldi L, Piccoli M, Frati L and Santoni A: Proline-rich tyrosine kinase 2 and Rac activation by chemokine and integrin receptors controls NK cell transendothelial migration. J Immunol 170: 3065-3073, 2003.

25. Oser $\mathrm{M}$ and Condeelis $\mathrm{J}$ : The cofilin activity cycle in lamellipodia and invadopodia. J Cell Biochem 108: 1252-1262, 2009.

26. van Rheenen J, Condeelis J and Glogauer M: A common cofilin activity cycle in invasive tumor cells and inflammatory cells. J Cell Sci 122: 305-311, 2009.

27. Pollard TD and Borisy GG: Cellular motility driven by assembly and disassembly of actin filaments. Cell 112: 453-465, 2003.

28. Sun CK, Ng KT, Lim ZX, Cheng Q, Lo CM, Poon RT, Man K, Wong N and Fan ST: Proline-rich tyrosine kinase 2 (Pyk2) promotes cell motility of hepatocellular carcinoma through induction of epithelial to mesenchymal transition. PLoS One 6: e18878, 2011 